\title{
Infección por VIH/SIDA en niños y adolescentes: cohorte chilena 1987-2014
}

\author{
Elba Wu, M. Isabel Galaz, Carmen Larrañaga, Ana Chávez, Marcela González, \\ Ana M. Álvarez, Anamaría Peña, Julia Villarroel y Eloísa Vizueta, \\ en representación del Comité de VIH/SIDA Pediátrico, Sociedad Chilena de Pediatría
}

\section{HIV/AIDS infection in children and adolescents: Chilean cohort 1987-2014}

The present document describes the Cohort of HIV/AIDS children detected in Chile from 1987 to August 2014 and the effectiveness of the Protocol for Prevention of Vertical Transmission (PPVT) of HIV infection. Of the 375 HIV infected children enrolled since 1987 to August 2014, 245 of them are still in pediatric control. From the analysis of the Cohort is inferred that: a) it has observed an improvement in the detection of the HIV infected child, in number and precocious time; b) the majority of these children continue to be detected by clinic symptoms and signs (mainly unspecific and infectious manifestations); c) the ARVT use has meant a clinic and immunologic improvement with diminution of the infections, principally opportunistic infections, with a better life quality, a prolongation of survival and a diminution of lethality; d) as more survival has been produced, cancer has begun to be detected, a very infrequent complication observed in them before the ARVT use. The PPVT started in 1995, and was reinforced in 2005 with the "Joint Norm of HIV and Syphilis Vertical Transmission Prevention" (MINSAL), both have meant a diminution of the HIV vertical transmission from $>35 \%$ (before 1995 ) to $<2 \%$ nowadays in the mother-child binomial; also have permitted a second generation of HIV exposed children born without infection. In spite this PPVT, still HIV infected child continue to be detected which imply failures in some points of the health system.

Key words: HIV AIDS, antiretroviral therapy vertical transmission.

Palabras clave: VIH, SIDA, terapia anti-retroviral, transmisión vertical.

\section{Introducción}

S egún ONUSIDA/OMS, desde el inicio de la epidemia en 1981 y hasta fines del año 2013, aproximadamente 78 millones [71-87 millones] de personas contrajeron la infección por el VIH y 39 millones [35-43 millones] de personas han fallecido a causa de enfermedades relacionadas con el virus de la inmunodeficiencia humana/síndrome de inmunodeficiencia adquirida (VIH/ SIDA). En el año 2013, 35 millones [33,2-37,2 millones] de personas padecían de la infección por VIH y de ellas, prácticamente la mitad eran mujeres ${ }^{1}$.

Los primeros casos de SIDA en niños fueron descritos en el mundo en 1982, adquiridos por transfusiones, $y$ en 1983 los por transmisión vertical (TV), madre-hijo ${ }^{1}$. En Chile, los primeros casos de VIH/SIDA en adultos fueron descritos los años 1984 en hombres y 1985 en mujeres. Los primeros casos de VIH/SIDA en niños fueron descritos los años 1987 (transfusional) y 1989 (vertical) $^{2}$. Estos niños fueron detectados en base a sospecha clínica, siendo el diagnóstico de VIH confirmado posteriormente por exámenes de laboratorio (serología). El primer caso fue un niño de 12 años que a raíz de una operación por quemaduras eléctricas recibió cinco transfusiones, dos de las cuales resultaron proceder de donantes con infección por VIH. A raíz de este niño, se implantó en Chile la detección del VIH en todos los bancos de sangre. Los primeros casos descritos por TV fueron un par de gemelos, cuya madre había contraído el VIH por transfusión y cuyo diagnóstico fue efectuado casi al mismo tiempo que el de sus hijos en otro centro asistencial.

Como consecuencia, principalmente, del aumento de la transmisión heterosexual en adultos y, en menor proporción, del aumento de mujeres drogadictas (especialmente por drogas endovenosas), se produjo a continuación en el mundo, incluido Chile, un rápido y sostenido incremento de casos de infección por VIH/SIDA en mujeres (tendencia a la feminización) y por lo tanto, en niños. Así, actualmente la mayoría de los adultos infectados están en edad de procrear y casi la mitad de los adultos en edad de procrear son mujeres, y más de 3 millones tienen menos de 15 años de edad (asintomáticos y sintomáticos) $)^{1-3}$.

Desde el momento en que en el mundo se han ido implementando medidas de prevención de la transmisión del VIH tanto en adultos como en la mujer embarazada y se ha incrementado el número de personas que tienen
Universidad de Chile, Santiago. Facultad de Medicina Occidente (EWH) Hospital San Juan de Dios, Santiago. (EWH, AMAP, CL) Hospital Roberto del Río, Santiago (MIG)

Hospital Exequiel González Cortés, Santiago (AC). Hospital Gustavo Fricke (MG). Hospital Sotero del Río, Santiago (AP). Hospital Félix Bulnes, Santiago (JV). Hospital San Borja Arriarán, Santiago (EV).

Conflictos de interés: No. Fuente de financiamiento: No.

Recibido: 7 de octubre de 2015 Aceptado: 23 de marzo de 2016

Correspondencia a: Elba Wu Hupat shuanwh@gmail.com 
acceso a la terapia anti-retroviral (TARV), el número de nuevos infectados ha ido en disminución y el número de personas infectadas por VIH/SIDA ha aumentado gracias a la mayor sobrevida de las personas accediendo a la TARV ${ }^{1}$. Así, desde el año 2001 se ha producido una reducción mundial de $38 \%$ de nuevas infecciones por VIH siendo esta reducción mayor en niños (58\%). A esta disminución de nuevas infecciones por VIH en niños ha contribuido el mayor acceso al tratamiento de las mujeres embarazadas. Según ONUSIDA, a fines del año $2010,48 \%$ de las mujeres embarazadas infectadas por VIH tuvieron acceso a TARV, cifra que aumentó a $62 \%$ el año 2012 y en numerosos países el índice de cobertura fue superior a $80 \%$. A su vez, el gran aumento experimentado en el acceso a la TARV está contribuyendo a salvar más vidas. Así, desde el año 2005, año con el pico de fallecidos, se han reducido las muertes relacionadas con el VIH en $35 \%{ }^{4-7}$.

Según la clasificación de 1994 del Centers for Disease Control and Prevention (CDC) de los Estados Unidos de América (E.U.A.), la infección por VIH en niños se define como aquella que ocurre bajo de 13 años ${ }^{8,9}$. Más de $90-95 \%$ de los niños infectados en el mundo lo han sido por TV, la que puede producirse en cualquier período del embarazo, durante el trabajo de parto/parto o en el período postnatal (especialmente por lactancia materna), siendo más frecuente que ocurra a fines del embarazo y en el período intra-parto $(50-70 \%)^{10}$. El riesgo de que una mujer infectada con VIH transmita el virus al hijo(a) en gestación, si no se adoptan medidas preventivas, varía entre 15 y $45 \%$-las cifras mayores se describen en países africanos- siendo lo más frecuente alrededor de 25 a $35 \%$. Cifras en estos rangos se observaron en Chile hasta antes de la incorporación de Protocolos de Prevención de la TV (PPTV) del VIH con anti-retrovirales ${ }^{11-16}$.

Con la aplicación de TARV preventiva de la TV del VIH y/o terapéutica de la infección por VIH más otras medidas, se ha logrado disminuir la TV de este virus a $\pm 1-2 \%$ en E.U.A., Europa y muchos otros países, incluido Chile $1-2,4-7,11-12,15-21$; con ello, en estos lugares la aparición de nuevos casos de niños infectados con VIH ha sido menor.

En 1990 se constituyó el Comité Nacional de VIH/ SIDA Pediátrico de la Sociedad Chilena de Pediatría (SOCHIPE) el que cuenta con representantes de todo el país y sus objetivos han sido la difusión de esta patología, la pesquisa de niños expuestos al VIH (hijos de madres seropositivas) y de niños infectados con VIH, así como la elaboración de pautas de estudio y manejo, más la prevención y tratamiento de ellos. Para ello este Comité trabaja en conjunto con el Departamento de Programas de ITS y VIH / SIDA (ex CONASIDA), MINSAL ${ }^{22,23}$.

En Chile, desde los primeros casos pediátricos de VIH/SIDA hasta agosto de 2014, se han diagnosticado 375 niños según cifras del Instituto de Salud Pública
(ISP): 355 por TV (95\%) y 20 por transmisión horizontal (transfusionales, abuso sexual, otros) ${ }^{24}$.

\section{Objetivos}

Presentar la cohorte con los datos de niños y adolescentes con infccción por VIH/SIDA que han sido detectados en Chile desde 1987, año de pesquisa del primer niño con esta patología por transmisión horizontal (vía transfusiones) hasta agosto de $2014^{19}$.

Dentro de esta cohorte se incluyen los datos de una evaluación efectuada el año 2008 con los niños detectados entre 1987 y ese año ${ }^{18}$, y los datos de la evolución de la TV del VIH desde la aplicación en este país de PPTV (año 1995) 17,20,21,24.

\section{Metodología}

La creación del Comité Nacional de VIH/SIDA Pediátrico conllevó aparejada varias acciones:

- La designación de encargados de aplicar la normativa nacional de manejo de los pacientes diagnosticados con la infección y de los neonatos expuestos durante su gestación a la infección por VIH. Se designó uno o más por cada hospital público en la Región Metropolitana (en total: 12) y uno por cada una de las otras regiones administrativas (n: 12), perteneciente habitualmente al hospital regional de mayor jerarquía. Integró también este comité un representante del Instituto de Salud Pública, en su Laboratorio Nacional de Referencia que centraliza la confirmación del diagnóstico de infección por VIH, observando los criterios definidos por el CDC de E.U.A. para la Pediatría.

- La capacitación periódica de los encargados de ejecutar el Programa de VIH/SIDA pediátrico, con énfasis en los criterios de confirmación de la infección por $\mathrm{VIH}$ y de inicio de TARV.

- El desarrollo anual de talleres para conocer y analizar los casos nuevos detectados, año a año, como así las novedades introducidas al manejo de los pacientes.

- El registro clínico periódico, detallado y centralizado, de la información emanada de cada centro responsable del Programa de VIH/SIDA Pediátrico.

En nuestro país, los servicios pediátricos atienden regularmente adolescentes hasta cumplir 15 años aunque para algunas patologías se extiende este límite hasta los 18 años, por conveniencias en su atención y seguimiento. El Programa de VIH/SIDA Pediátrico incluye en Chile la atención de pacientes hasta los 18 años de edad, momento en que son transferidos a servicios clínicos de adultos. Esto significa el seguimiento hasta esta edad de los pacientes detectados en los primeros meses/años de vida como así también los que son detectados durante su adolescencia 
temprana y mediana (antes de los 15 años de edad). Pacientes que figuran en esta cohorte, con edad superior a 18 años, están fuera de lo establecido en el protocolo.

\section{Resultados}

De los 375 niños detectados hasta agosto de 2014, 245 niños y adolescentes se mantienen en control, 18 adolescentes han sido trasladados al programa de adultos, 73 han fallecido por causas relacionadas a la infección por VIH/SIDA y por otras causas, y 39 se han perdido de seguimiento.

Según los datos obtenidos hasta el año 2008, la mayoría de los casos se concentraba en la Región Metropolitana (RM) (58\%); según los datos actuales la distribución es similar en la RM (49\%) que en el resto de las regiones $(51 \%)$. La distribución actual de los casos por Centro se señala en la Figura 1.

Hay un predominio del sexo femenino (53\%) por sobre el masculino (47\%).

El promedio de edad al diagnóstico fue de 2 años 4 meses, con un rango de 1 mes a 14 años; $46 \%$ fue detectado antes del año de edad, $41 \%$ entre los 13 meses a 5 años, $10 \%$ entre los 61 meses a 10 años y 3\% a una edad superior a 10 años. El promedio de edad de los pacientes actualmente en control es de 11 años, con un rango de 1 a 21 años: $30 \%$ tienen bajo 10 años $(<5$ años $9,5 \%$, entre 5 $\mathrm{y}<10$ años $20,5 \%)$ y $70 \%$ sobre 10 años $(10 \mathrm{a}<15$ años $38 \%$ y sobre 15 años $32 \%$ ), es decir las dos terceras partes de los pacientes están ya en la adolescencia (Figura 2).

La mayoría de los niños ha sido detectada por sus manifestaciones clínicas, ya sea como antecedentes o manifestaciones presentes en el momento de la consulta (47\% hasta el año 2008, 42\% en la actualidad). La detección en base a antecedentes maternos ha sido en alrededor de un tercio de los casos (35\%) y por ingreso a PPTV en un menor porcentaje (10\%).

La mayoría de los niños detectados por clínica lo fueron por manifestaciones inespecíficas e infecciones. Entre las infecciones, presentes en el debut o durante la evolución de estos niños, las más frecuentes fueron bacterianas (neumonías, septicemias, meningitis), por microorganismos causales habituales de la infancia; aquellas causadas por agentes oportunistas, principalmente citomegalovirus (CMV) y Candida spp y, menos frecuentemente Pneumocystis jiroveci, Cryptosporidium, virus herpes simplex (VHS), Mycobacterium tuberculosis y Mycobacterium avium (MAC). Las manifestaciones hematológicas, nutricionales y neurológicas (paraparesia espástica, hipotonía, microcefalia) estuvieron presentes en menos casos.

Hasta el año 2008, 41\% de los niños había sido detectado en etapa de SIDA y $59 \%$ en etapas no SIDA.

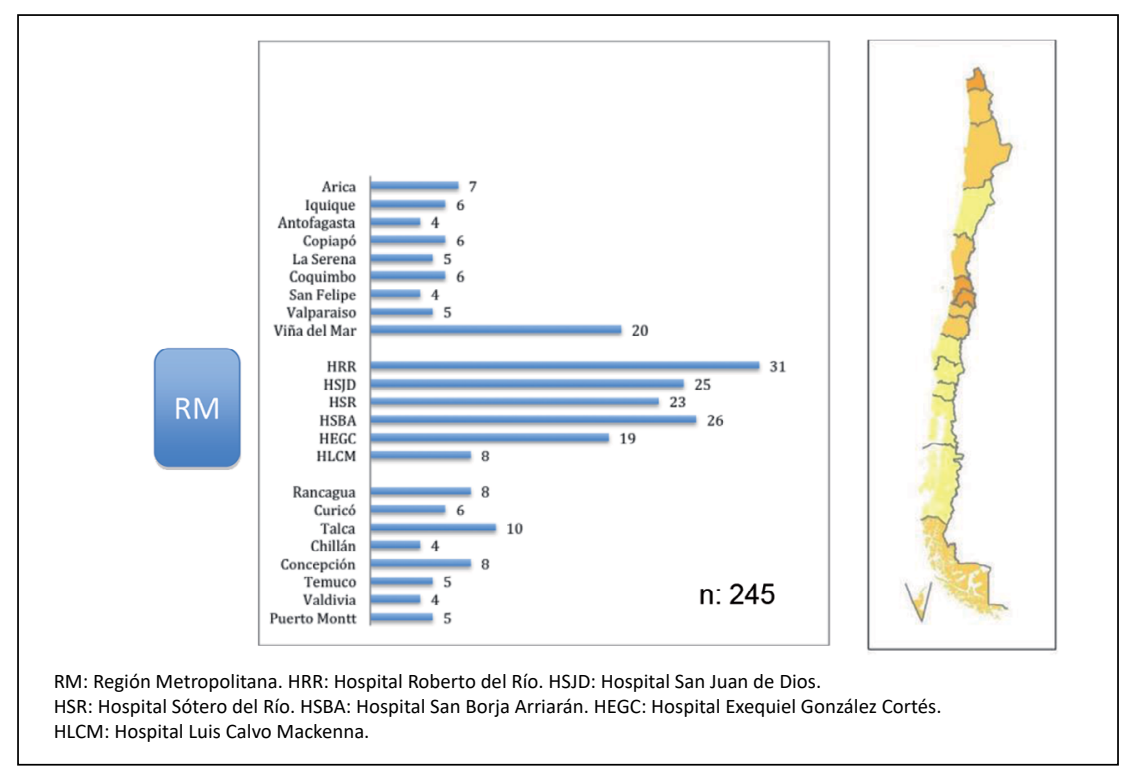

Figura 1. Distribución de pacientes pediátricos con VIH/SIDA en control.

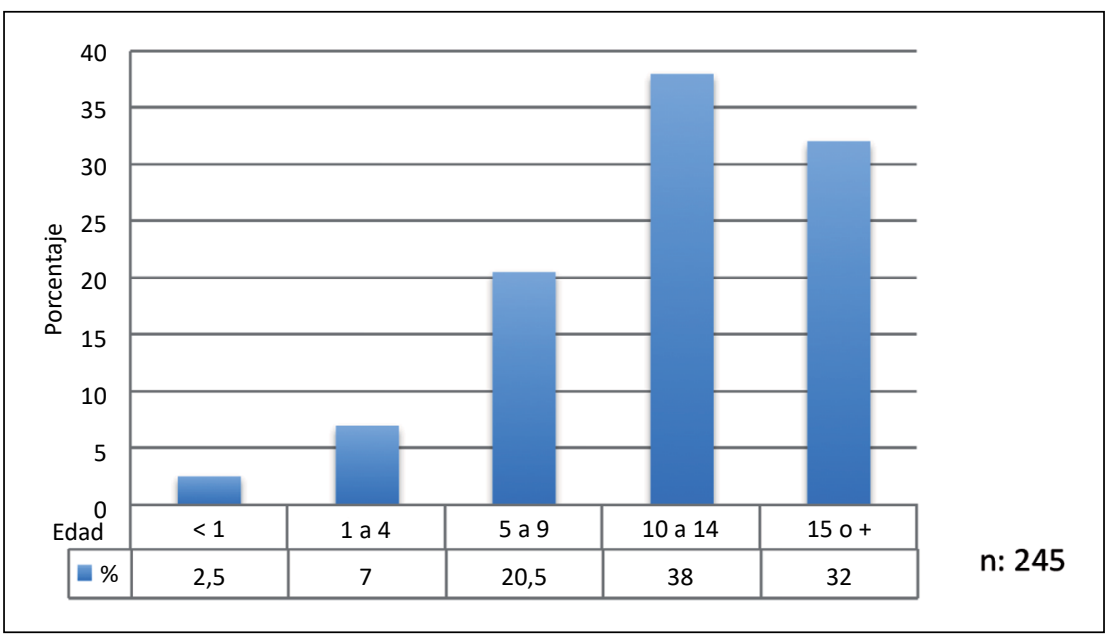

Figura 2. Distribución de pacientes con VIH/SIDA en control, según edad.

Actualmente, estas cifras son de 27,8 y $72 \%$, respectivamente (etapa $\mathrm{N}[17,8 \%$ ], etapa A [26\%] y etapa B [28,2\%]) (Clasificación CDC 1994 para niños infectados con VIH).

La indicación de TARV en los niños chilenos se inició con biterapia en el año 1996 pasando a triterapia el año 1998, usando los anti-retrovirales y pautas disponibles en ese momento. Actualmente, $92 \%$ de los niños y adolescentes controlados por el Comité se encuentran en TARV y $8 \%$ aún no la inician. De los pacientes en TARV, la edad promedio de inicio de la terapia fue 3 años y 2 meses (rango: 1 mes a 15 años). Alrededor de un tercio inició TARV durante el primer año de vida, otro tercio 
entre el año y los 5 años, $15 \%$ entre los 5 y 10 años y $5 \%$ sobre los 10 años. Hasta la fecha, las tres cuartas partes de los pacientes ha usado uno o dos esquemas de TARV (Figura 3) con esquemas, en general, de primera línea. La minoría ha necesitado esquemas de tercera línea o de rescate. Los esquemas de triterapia más frecuentemente usados contemplan una base de dos inhibidores de transcriptasa reversa análogos de nucleósidos (ITRANs) + un inhibidor de transcriptasa reversa no nucleósidos (ITRNN) (nevirapina o efavirenz) (47\%) y una base de dos ITRANs + un inhibidor de proteasa (IP), principal-

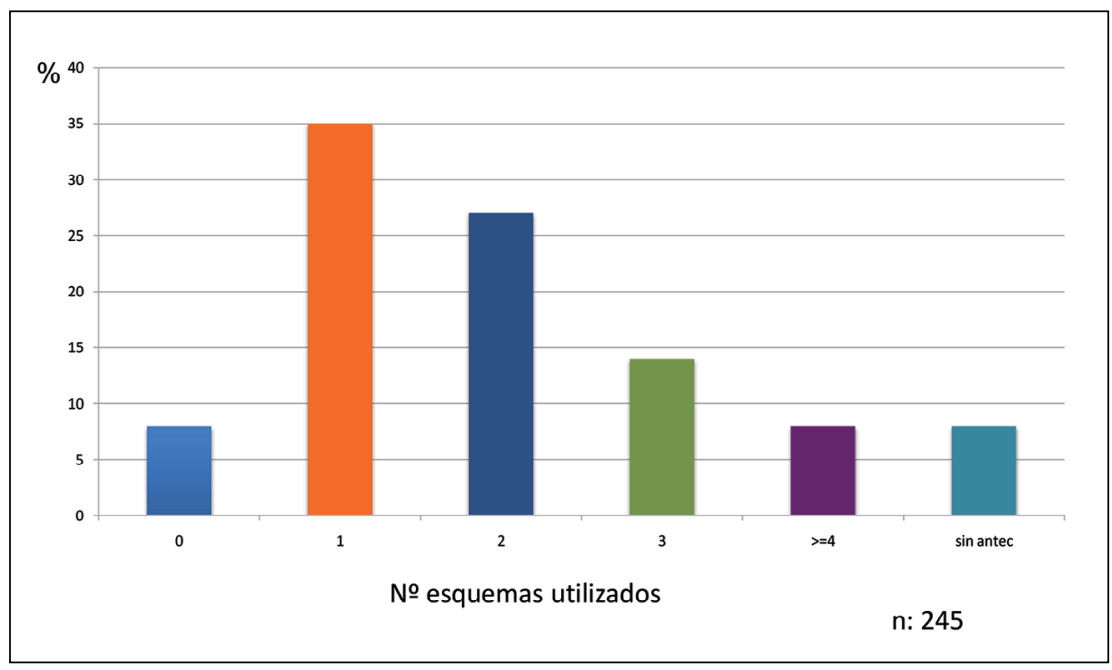

Figura 3. Distribución de pacientes con VIH/SIDA según número de esquemas de TARV utilizados.

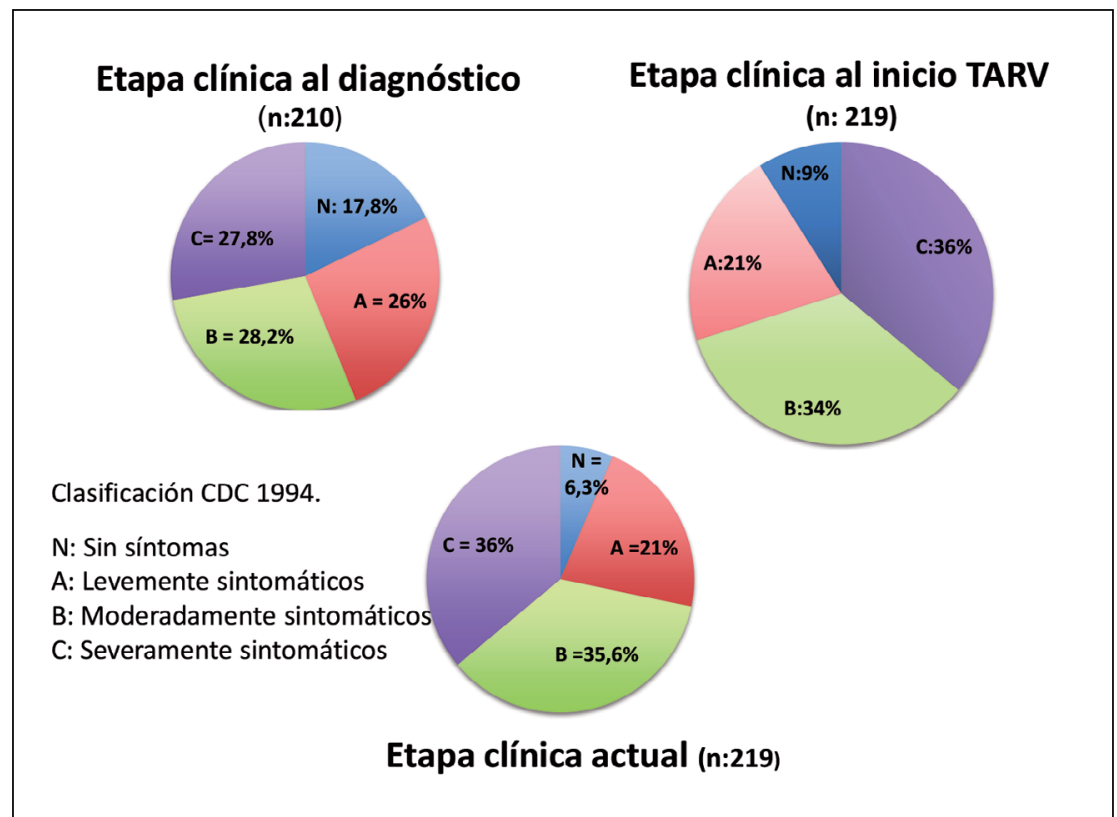

Figura 4. Evolución etapas clínicas (Clasificación CDC 1994). mente lopinavir/ritonavir (LPV/rtv), y, menos frecuente, atazanavir/ritonavir (ATV/rtv) (37\%). Otros esquemas de triterapia como un ITRAN + un ITRNN + un IP, un ITRAN + dos IPs o tres ITRANs, han sido usados con menor frecuencia. Lo mismo el uso actualmente de biterapia (un ITRNN + un IP).

Los casos que aún no inician TARV fueron diagnosticados entre los años 2004 y 2013. El promedio de edad al diagnóstico de estos pacientes fue 4 años. Setenta y cinco por ciento fue diagnosticado después de los 2 años (rango 12 meses a 10 años). El promedio de edad actual de los pacientes sin TARV es 8 años; $87 \%$ tienen sobre 6 años de edad (rango 1 a 16 años). Treinta y uno por ciento se mantiene en etapa clínica N, 50\% en etapa A y el resto en etapa B; $80 \%$ se mantiene en estadio inmunológico 1 y $20 \%$ en estadio 2 (Clasificación CDC 1994 para niños con infección por $\mathrm{VIH}$ ) .

Según datos obtenidos, en el año 2008 el cuidado de los niños y la responsabilidad en el cumplimiento del tratamiento radicaba en la familia biológica (padre, madre, abuelos, tíos) (84\%), en una familia sustituta (5\%), en padres adoptivos (1\%) y $10 \%$ estaba en un hogar para niños infectados con VIH (10\%).

La adherencia a TARV fue excelente o buena en $73 \%$ de los pacientes (excelente $32 \%$, bueno $41 \%$ ) y regular o mala en el $27 \%$ (regular $19 \%$ y mala $8 \%$ ). Estos datos no fueron evaluados el año 2014.

Las etapas clínicas (Clasificación CDC 1994 para niños con infección por VIH) al diagnóstico, al inicio de la TARV y en la actualidad se muestran en la Figura 4. De los pacientes detectados en etapas no SIDA (44\% en etapas $\mathrm{N}$ y A y $28 \%$ en etapa B) destacan las infecciones respiratorias frecuentes, tanto altas como bajas. De los pacientes detectados en etapa C, (SIDA), (28\%) las infecciones más frecuentes descritas fueron neumonía y enfermedad diseminada por CMV, neumonía por $P$. jiroveci, neumonías bacterianas a repetición y septicemias graves. Al inicio de la TARV las etapas $\mathrm{B}$ y $\mathrm{C}$ habían aumentado a 34 y $36 \%$, respectivamente.

En la Figura 5 se compara la etapa inmunológica (Clasificación CDC 1994 para niños con infección por VIH) al diagnóstico con las etapas inmunológicas al inicio de la TARV y en la actualidad. Se observa que, al momento del diagnóstico de $\mathrm{VIH}$, el porcentaje de niños que se encontraba en cada una de las etapas inmunológicas era más o menos similar (30\% o más). Al inicio de la TARV, el porcentaje de niños con compromiso inmunológico grave (etapa 3 ) había aumentado a $67 \%$, por disminución de las etapas $2(22 \%)$ y especialmente de la $1(11 \%)$. Con el uso de la TARV y la consiguiente recuperación inmune hubo un aumento de los pacientes en etapa 1 (sin supresión inmune) que llegó a 70\% y una disminución a $8 \%$ de los niños en etapa 3 . No hubo cambios en el porcentaje de la etapa inmunológica 2. 
Con la aplicación en binomios madre-hijo de PPTV del VIH (uso de anti-retrovirales más otras medidas de prevención como cesárea electiva antes de $4 \mathrm{~h}$ de rotura de membranas y lactancia artificial), se logró una reducción de la TV del VIH desde $30-35 \%$ en el período anterior a 1995 (sin protocolos) hasta 9,5\% a fines de 1997 con el uso del protocolo PACTG 076 original (sólo con zidovudina); su continuación en los años siguientes y la incorporación en la embarazada de biterapia (zidovudina + lamivudina) y actualmente de triterapia anti-retroviral, disminuyó la TV a 2\% entre 1998 y julio de 2005, cifra que se mantiene hasta ahora en los binomios en que se ha aplicado. Entre los años 1998 y julio de 2005 nacieron sólo 8 niños infectados de 401 binomios madre-hijo que recibieron medidas preventivas de la TV (TV $2 \%$ ), lo que contrasta con 162 niños con infección por VIH que han sido detectados hasta fines del 2013 y que nacieron en el período del estudio de madres que no fueron beneficiadas con alguna medida de prevención (111 detectados entre 1998 y julio de 2005, y 51 desde esa última fecha hasta fines de 2013).

Entre el año 2006 y julio de 2014, (años en que ya rige en Chile la Norma de Prevención de la TV del VIH, se han detectado 127 niños infectados con VIH, de los cuales la mitad (n: 63) nació el mismo año del diagnóstico (Figura 6). De éstos, en 59 casos la adquisición de la infección fue por TV y de ellos, la mitad (n: 29) no recibió PPTV del VIH y la otra mitad (n: 30) sí. De las mujeres embarazadas sin PPTV, destaca que la mitad (n: 14) no lo recibió porque tuvieron un examen negativo de ELISA para VIH durante la gestación. De las que recibieron PPTV, sólo en un tercio fue completo (TARV antenatal, natal y en el recién nacido, más las otras medidas señaladas) por ser diagnosticadas como infectadas por VIH, antes o durante el embarazo;

Etapa inmunológica al diagnóstico

Etapa inmunológica al inicio TARV

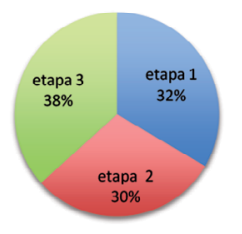

Etapa inmunológica actual

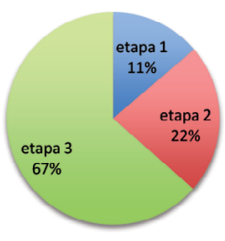

Clasificación CDC 1994

Etapa 1

Etapa 2

Etapa 3

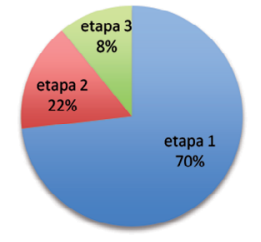

Figura 5. Evolución etapas inmunológicas (Clasificación CDC 1994).

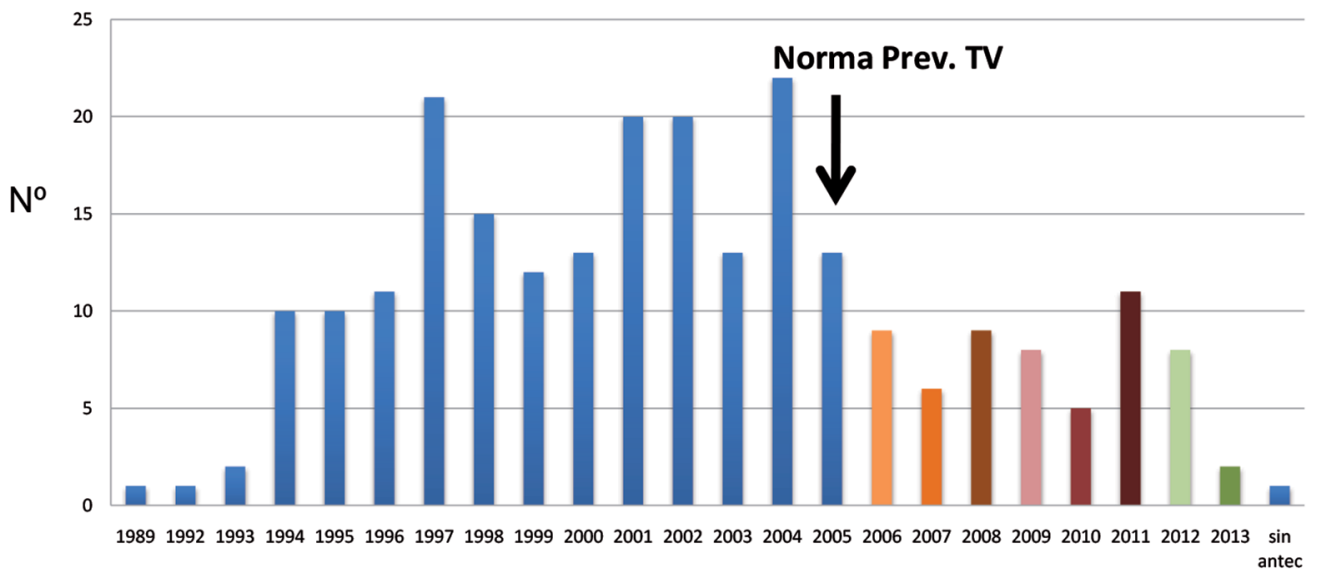

\begin{tabular}{|l|c|c|c|c|c|c|c|c|c|c|c|c|c|c|c|c|c|c|}
\hline Año & $94-98$ & 99 & 2000 & 01 & 02 & 03 & 04 & 05 & 06 & 07 & 08 & 09 & 10 & 11 & 12 & 13 & 14 & Total \\
\hline $\begin{array}{l}\text { Nacidos año } \\
\text { detección }\end{array}$ & 24 & 3 & 5 & 5 & 5 & 4 & 5 & 1 & 2 & 2 & 3 & 1 & 2 & 7 & 4 & 2 & 1 & 76 \\
\hline $\begin{array}{l}\text { Total detectados } \\
\text { por año }\end{array}$ & 65 & 11 & 12 & 22 & 19 & 11 & 21 & 14 & 8 & 7 & 9 & 2 & 3 & 10 & 6 & 2 & 1 & 223 \\
\hline \multicolumn{10}{|c|}{ Niños VIH (+) por TV } \\
\hline
\end{tabular}

Figura 6. Niños $\mathrm{VIH}(+)$ por $T V$, detectados por año nacimiento/total por año. 
en el resto fue incompleto (TARV sólo en el período del parto y en el recién nacido o sólo en el recién nacido con todas o sólo alguna(s) de las otras medidas preventivas), debido al diagnóstico tardío de la infección por VIH y/o a varias otras causas. Todo esto ha significado que se mantenga la transmisión en $\pm 2 \%$ en aquellos binomios con prevención de la TV completa o incompleta.

De 223 niños infectados con VIH por TV, sólo 76 fueron diagnosticados el año de nacimiento (34\%); los demás lo fueron en edades más tardías generalmente por manifestaciones clínicas. El 78,5\% de los niños infectados con VIH por TV fueron detectados antes del año 2005 (año de implementación de la Norma de Prevención de la TV del VIH) y de ellos, sólo $30 \%$ fue diagnosticado el año de nacimiento. De $21,5 \%$ de niños pesquisados desde el año 2006 al 2014, 50\% lo fue el año de nacimiento (Figura 6).

Del total de 375 pacientes pediátricos diagnosticados por el ISP desde 1987 al año 2014, han fallecido 73 $(19,6 \%)$. Treinta y tres casos $(45 \%)$, fallecieron en el período anterior al año 2000, 25 casos (34\%) entre el año 2000 y el 2005 y 15 (20,5\%) entre el 2005 y el 2014 (Figura 7). En el primer período, las causas de muerte fueron principalmente infecciosas $(70 \%)$, por agentes bacterianos y oportunistas, especialmente CMV. Varios de los fallecidos fueron pesquisados ya en etapa de SIDA en los primeros meses de vida o incluso post mortem, la mayoría con neumonía por CMV; $100 \%$ de los fallecidos no había recibido TARV. En el segundo período disminuyeron las infecciones como causa de muerte, igualándose las oportunistas y las bacterianas y aparecen los cánceres; $36 \%$ de los fallecidos recibió TARV. En el tercer período se observa una mayor disminución de las infecciones

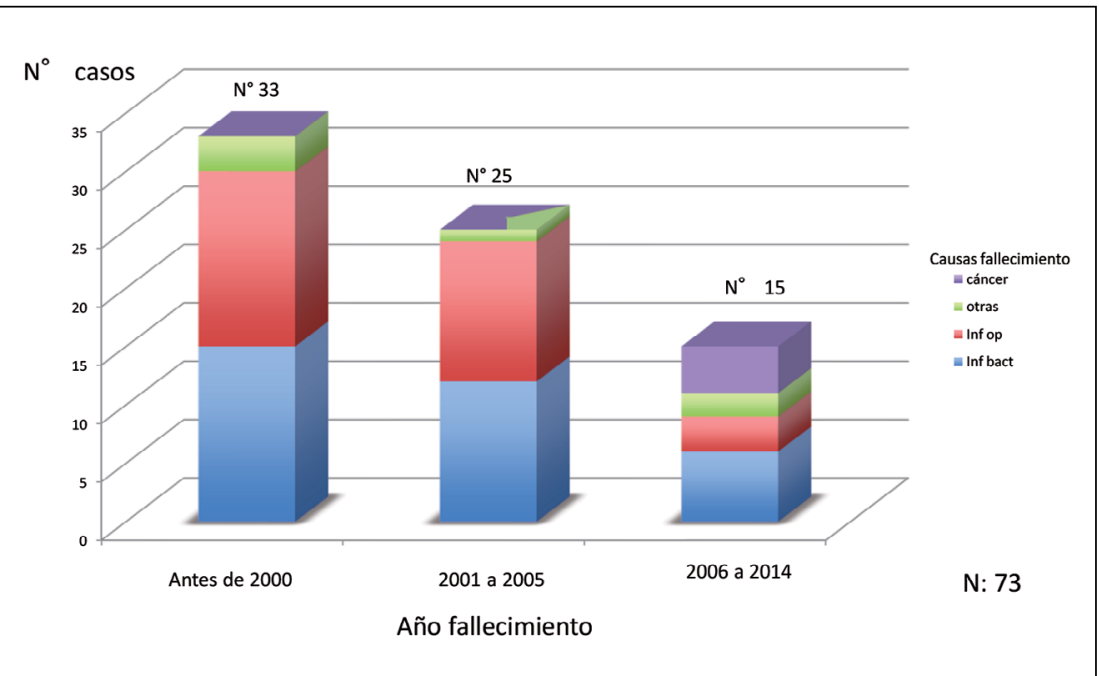

Figura 7. Número fallecidos y causas de muerte por VIH/SIDA, por períodos. como causa de muerte, especialmente de las infecciones oportunistas, y aumentan los cánceres (cáncer testicular, tumor de fosa posterior, linfoma, tumor de Wilms); 87\% recibió TARV (Figura 7).

De los primeros niños detectados por el Comité, varios ya han llegado a ser adolescentes y adultos jóvenes. De este grupo cinco mujeres se han embarazado y sus hijos/as han nacido sin la infección del VIH gracias a la aplicación de los PPTV de VIH.

\section{Discusión}

La evaluación de la cohorte de niños y adolescentes infectados con VIH y de la evolución de la TV del VIH, revela los progresos que se han visto en Chile en la infección por VIH/SIDA desde la detección del primer caso pediátrico en 1987 (transfusional) y de la constitución del Comité de VIH/SIDA Pediátrico, en 1990 hasta la fecha.

En Chile, gracias a la implementación en 1987 de la detección de VIH en todos los bancos de sangre, no se han detectado nuevos niños infectados por transfusiones, siendo los últimos casos de transmisión horizontal producidos por abuso sexual y causas desconocidas ${ }^{24}$.

El manejo de estos niños por el Comité ha sido multidisciplinario, iniciado desde el nacimiento en los recién nacidos $(\mathrm{RN})$ expuestos y desde el momento de su pesquisa en los niños detectados posteriormente en la vida. Los progresos se han evidenciado en la pesquisa cada vez más precoz de los niños infectados con VIH, en el acceso a TARV de todos los casos que lo ameritan, en la prolongación de la sobrevida con mejor calidad de vida y menos letalidad, en la disminución de la TV del VIH en aquellos binomios madre-hijo con PPTV, y en el tener una segunda generación de niños sanos, hijos de madres que adquirieron el VIH por TV.

Desde los primeros casos de niños con infección por VIH detectados en 1987 y 1989 (transfusional y por TV respectivamente $)^{2,11,12}$ ha habido una mejoría en todo el país, tanto en el número de casos pesquisados como en su detección más precoz: hasta el año 2008 la mayoría de los casos se concentraba en la RM y en la actualidad, los casos ocurridos en la regiones igualan a los de la RM; hasta el año 2008, 41\% de los casos fue detectado en etapa de SIDA y $59 \%$ en etapa de no SIDA, en la actualidad estas cifras son 28 y $72 \%$, respectivamente ${ }^{18,19}$. Hasta antes de la implementación de la Norma de Prevención de la TV del VIH (año 2005), 70\% de los niños era pesquisado tardíamente (después de año de vida); desde ese año, esta cifra ha ido en descenso $(50 \% \text { actualmente })^{19}$.

Entre los progresos de las políticas de control del VIH en nuestro país destaca el inicio de TARV en todos los niños en que estuviera indicada. Esto comenzó el año 1996 con biterapia que en esos años consistía en 
dos de los ITRANs disponibles: zidovudina (ZDV), lamivudina (3TC), didanosina (ddI) y estavudina (d4T); en el año 1998 se pasó a tri-terapia con una base de dos ITRANs más un ITRNN o un $\mathrm{IP}^{25,26} \mathrm{El}$ primer ITRNN usado fue nevirapina (NVP) agregándose posteriormente efavirenz (EFV), y el primer IP usado fue ritonavir (RTV) agregándose posteriormente LPV/rtv y mucho después, otros IPs. La mayoría de los pacientes ha usado uno o dos esquemas de TARV, en general, de primera línea (ZDV, 3TC, abacavir [ABC], NVP, EFV, LPV/rtv, ATV/rtv); sólo cerca de $15 \%$ está con esquemas de anti-retrovirales de segunda línea o de uso más reciente en niños, como tenofovir (TDF, un ITRAN), etravirina (ETV, un ITRNN), darunavir (DRV, un IP), raltegravir (RAL, un inhibidor de integrasa), enfuvirtide (T20, un inhibidor de entrada, de fusión) y maraviroc (MRV, un inhibidor de entrada, de CCR5) $)^{22,23,26}$. En los primeros años, el inicio de TARV en los niños era más tardío, ya fuese porque ingresaban en etapa de SIDA y/o en etapa inmunológica 3, (inmunosupresión grave), o por deterioro clínico y/o inmunológico y/o virológico durante la evolución (Figuras 4 y 5) $8,9,18,25,26$. El haber sido más conservadores que en otros países en el inicio de TARV explica que la mayoría de los niños y adolescentes hayan recibido uno o dos esquemas de TARV y que sólo un bajo porcentaje haya tenido que usar anti-retrovirales de segunda línea o que han sido aprobados recientemente para su uso en niños ${ }^{19}$. Según las guías actuales $22,23,26,28$, el inicio de la TARV, tanto en niños como en adultos, debiera ser más precoz (incluso se debe iniciar la TARV en todo lactante menor de un año infectado con VIH, de manera independiente de la etapa clínica e inmunológica). El 8\% de niños que aún no inician TARV es porque no cumplen los criterios clínicos y/o inmunológicos de inicio actuales ${ }^{22-23,26-28}$.

Con el uso de TARV y otras medidas preventivas y terapéuticas y la consiguiente recuperación inmune (disminución de pacientes en etapa 3 al inicio de la TARV, de 67 a $8 \%$ con la terapia, Figura 5) y recuperación clínica que se ha producido, en la mayoría de los casos han disminuido las infecciones (especialmente las oportunistas y menos las bacterianas), ha mejorado la calidad de vida, aumentando la sobrevida, y con ello han aparecido cánceres antes muy infrecuentes en niños, y ha disminuido la letalidad ${ }^{19,29-39}$. En la Figura 4, etapas clínicas, no se ven cambios en los porcentajes, pues un niño infectado con VIH clasificado en una categoría debe ser mantenido en ella aunque haya mejorado espontáneamente o mediante tratamiento. De los 73 muertos, la mayoría (45\%) falleció antes del año 2000, no recibió TARV y las causas de muerte fueron especialmente las infecciones oportunistas y bacterianas; en los períodos siguientes aumenta el uso de TARV, disminuyen las infecciones, especialmente las oportunistas, y aparecen los cánceres como causa de muerte ${ }^{19,38}$.
Otro logro importante en la prevención de la infección por VIH/SIDA en niños ha sido la implementación de PPTV. Los PPTV del VIH incluyen: en la mujer embarazada detectar si está infectada con VIH, ofrecerle TARV preventiva de la TV del VIH y/o terapéutica de su infección por VIH, más otras medidas preventivas como cesárea electiva (parto podría ser vaginal sólo si la carga viral es indetectable o $<1.000$ copias ARN/ml al momento del parto, además de otras consideraciones) y que la rotura de membranas no sea mayor de $4 \mathrm{~h}$; en el RN, reemplazar la lactancia materna por leche artificial y seguir con el protocolo de anti-retrovirales preventivos durante seis semanas. El uso de anti-retrovirales en la mujer embarazada ha pasado de monoterapia (zidovudina: Protocolo PACTG-Paediatric AIDS Clinical Trials Group- 076 original de 1994) a bi-terapia (ZDV + 3TC) a tri-terapia en la actualidad (ZDV $+3 \mathrm{TC}+$ un IP, generalmente LPV/RTV, o el ITRNN NVP; con menos frecuencia se usan otros ARVs en la triterapia) ${ }^{13-16}$. Los PPTV del VIH se comenzaron a aplicar en Chile ya desde el año 1995 y con ello hubo una disminución drástica de la TV del $\mathrm{VIH}$ a $2 \%$ en aquellos binomios en que se aplicó ${ }^{17}$, pero sólo a partir del año 2006, fecha en que comenzó a regir la Norma de Prevención de la TV del VIH ${ }^{15,16}$ se notó una mayor disminución en el número de niños nacidos cada año con infección por VIH, pero sin llegar a cero, lo que significa fallas en algún punto del sistema de salud (Figura 6) ${ }^{20,21}$ debido a diagnóstico tardío de la infección por VIH y/o a varias otras causas como adherencia regular o mala, drogadicción, fallas en el sistema de salud (no ofrecimiento del examen de ELISA para VIH, no rescate del resultado, no ofrecimiento del PPTV, entre las más frecuentes). Esto implica la obligación del personal de salud correspondiente (médicos, matronas, enfermeras, etc.) de ofrecer el examen de ELISA para VIH a toda mujer embarazada, en forma independiente del período de gestación o del parto en que llega a control de salud, de rescatar el resultado, y el de ofrecer la TARV preventiva si el examen resulta positivo.

La Norma de PTV del VIH de 2005 ha experimentado algunos cambios en el año 2009 y, especialmente, en el 2013. Como con la implementación de la Norma de PTV del VIH por el CONASIDA en el año $2005^{15}$ no se ha llegado a cumplir con el objetivo de lograr una reducción de la TV del VIH a menos de $1 \%$ en Chile, en la Norma del año 2013 el objetivo se modificó para lograr a una TV de $2 \%$ o menos. Otros cambios en la Norma del año 2013 son:

- Ofrecer la ejecución del examen serológico de VIH (ELISA) en el primer control del embarazo (no en el segundo) previa entrega de información y firma del Consentimiento Informado o Denegación del Examen, con un segundo examen en la semana 32-34 en aquellas mujeres gestantes de mayor riesgo, $\mathrm{y}$ 
- A aquellas mujeres embarazadas con carga viral indetectable o menos de 1.000 copias ARN/ml en la semana 34 y que cumplan otras condiciones (TARV desde semana 24 , edad gestacional de 37 semanas, feto único, presentación cefálica y condiciones obstétricas favorables) plantearles la posibilidad de que el parto sea por vía vaginal ${ }^{15,16}$.

A pesar de los avances que ha habido en Chile en relación a la infección por VIH/SIDA, la mayoría de los niños infectados con este virus se siguen detectando en base a hechos clínicos (antecedentes o manifestaciones que presentan al momento de consultar), y la minoría por antecedentes maternos (diagnóstico de la infección en la madre durante el parto o en el período post-parto), siendo que en gran parte de ellos la infección pudo haberse prevenido con las estrategias vigentes desde $1995^{13,14}$. Ha contribuido a esto, la tardanza en dictar la Norma Conjunta de la Prevención de la Transmisión Vertical del VIH y Sífilis (año 2005) ${ }^{15}$ y su no cumplimiento por todo el personal de salud involucrado. La detección en base a las manifestaciones clínicas del niño, $47 \%$ hasta el año 2008 y $42 \%$ en la actualidad, fue principalmente por manifestaciones infecciosas, las que concuerdan con las descritas en la literatura científica ${ }^{29-38}$.

De los 63 niños nacidos desde el año 2006 a julio de 2014, sólo la mitad recibió PPTV. De los que no lo recibieron, la mitad fue por haber tenido una serología precoz en el embarazo negativa para VIH. El que durante este período hayan nacido 14 niños infectados con VIH que no recibieron PPTV por haber tenido serología negativa para este virus durante el embarazo, hace imperioso el efectuar una segunda prueba serológica para VIH a fines de la gestación a todas las mujeres embarazadas y no sólo a aquellas con factores de mayor riesgo como lo sugiere la norma del año $2013^{20,21}$.

El manejo multidisciplinario y total, con medidas preventivas y terapéuticas, ha permitido que $70 \%$ de los casos esté ya en la adolescencia y tener una segunda generación de hijos de madres infectadas con VIH que nacieron sin el virus gracias al uso en ellos de PPTV del $\mathrm{VIH}^{13-16,22,23,39}$

Agradecimientos. A Carolina San Martín y Claudia Bravo, del Instituto de Salud Pública, por su contribución a la certificación del diagnóstico de los niños infectados con VIH.

\section{Resumen}

Se presentan datos de la cohorte de niños con infección por VIH/SIDA detectados en Chile desde el año 1987 a agosto de 2014 y datos de la transmisión vertical (TV) del VIH con uso de protocolos de prevención de TV (PPTV). De los 375 niños infectados con VIH en este período, siguen en control pediátrico 245. Del análisis de la cohorte se desprende que: a) ha habido una mejoría en la pesquisa de los niños infectados con VIH, tanto en número como en precocidad; b) estos niños siguen detectándose, en su mayoría, por hechos clínicos (manifestaciones inespecíficas e infecciosas principalmente); c) el uso de TARV ha significado una mejoría clínica e inmunológica con disminución de las infecciones, principalmente las oportunistas, con una mejor calidad de vida, prolongación de la sobrevida, y disminución de la letalidad; d) por su mayor sobrevida, se ha observado el desarrollo de cánceres, muy infrecuentes en ellos antes del uso de terapia anti-retroviral. La aplicación de Protocolos de Prevención de la TV desde 1995, reforzada el 2005 con la "Norma Conjunta de la Prevención de la Transmisión Vertical del VIH y Sífilis” (MINSAL), ha significado una disminución de la TV del VIH desde más de $35 \%$ (antes de 1995) a $<2 \%$ actualmente en los binomios en prevención; además ha permitido que una segunda generación de niños expuestos al VIH nazca no infectada. A pesar de estos PPTV, aún siguen naciendo niños infectados con VIH, lo que implica fallas en algunos puntos del sistema de salud.

\section{Referencias bibliográficas}

1.- UNAIDS . Org UNAIDS Report on the Global AIDS Epidemic, 2013. http://www.unaids. org/sites/default/files/media_asset/UNAIDS Global_Report_2013_en_1.pdf

2.- García M, Olea A. Evolución y situación epidemiológica de la infección por virus de la inmunodeficiencia humana y síndrome de inmunodeficiencia adquirida en Chile. Rev Chilena Infectol 2008; 25: 162-70.

3.- UNAIDS. Report on the global HIV/AIDS epidemic, 2005. http://data.unaids.org/
Publications/IRC-pub06/epi_update2005_en.pdf

4.- UNAIDS.ORG. Eliminating new HIV infections among children, 2012. http://www.unaids.org/ en/resources/presscentre/featurestories/2012/ december/20121214gpmidterm

5.- UNAIDS.ORG: Global Plan towards the elimination of new HIV infections among children by 2015 and keeping their mothers Alive, 2011. http://www.unaids.org/sites/default/ files/media_asset/20110609_JC2137_GlobalPlan-Elimination-HIV-Children_en_1.pdf

6.- ONUSIDA. Comunicado de Prensa. En vísperas del Día Mundial del SIDA 2013, ONUSIDA señala un avance sostenido en la respuesta al SIDA, 2013.

7.- UNAIDS.Org. Global AIDS response progress reporting, 2014. http://www.unaids.org/sites/ default/files/media asset/GARPR 2014 guidelines_en_0.pdf http://www.unaids.org/ sites/default/files/media asset/GARPR 2014 guidelines_en_0.pdf

8.- CDC. Revision of the CDC surveillance Case definition for acquired immunodeficiency syndrome. MMWR Morbid Mortal Wkly Rep 1987; 36: 1S-15S.

9.- CDC: 1994 Revised Classification system for 
human immunodeficiency virus infection in children less than 13 years of age. MMWR Morbid Mortal Wkly Rep 1994; 43 (RR-12): 1-10.

10.- Newell M L. Mechanisms and timing of mother-to-child transmission of HIV-1. AIDS 1998; 12: 831-7.

11.- CONASIDA, Ministerio de Salud, Chile. Boletines epidemiológicos trimestrales, Serie Documentos CONASIDA .

12.- Comité Nacional de VIH/SIDA Pediátrico (SOCHIPE): Datos de Presentaciones a Congresos, Talleres, etc.

13.- CDC. Recommendations of the US Public Health Service Task Force on the use of zidovudine to reduce perinatal transmission of human immunodeficiency virus. MMWR Morbid Mortal Wkly Rep 1994; 43 (RR-11): $1-20$

14.- AIDS Info. Recommendations for use of antiretroviral drugs in pregnant HIV-1-infected women for maternal health and interventions to reduce perinatal HIV transmission in the United States. Ultima versión 28/03/2014, 1-225. https://aidsinfo.nih.gov/contentfiles/ perinatalg1003381.pdf

15.- CONASIDA, Ministerio de Salud, Chile Norma para Prevención de la Transmisión Vertical del VIH, 1a Ed. Agosto 2005, 2a 2009 y 3 a 2013.

16.- Programa Nacional de Prevención y Control de la infección por VIH/SIDA e ITS, División de Prevención y Control de Enfermedades, Subsecretaría de Salud Pública, Ministerio de Salud. Norma Conjunta de Prevención de la Transmisión Vertical del VIH y la Sífilis. Rev Chilena Infectol 2013; 30: 259-302.

17.- Chávez A, Álvarez A M, Wu E, Peña A, Vizueta E, y Comité Nacional de VIH/SIDA Pediatrico, Sociedad Chilena de Pediatría. Evolución de la transmisión vertical de la infección por VIH en Chile. Rev Chilena Infectol 2007; 24:368-71.

18.- Larrañaga C, Wu E, Álvarez A M, Chávez A, Vizueta E, Peña A M, Galaz M I, Bravo C L, por Comité VIH/SIDA Pediátrico, Chile. Evaluación de la Cohorte Nacional de VIH/SIDA Pediátrico, Chile 1987-2008. Presentado en: XIII Congreso Latinoamericano de Infectología Pediátrica, SLIPE, IV Congreso Ecuatoriano de infectología, Guayaquil, Ecuador, 12-15/08/09, Libro de Resúmenes, VIH-5, pág 35, y en XII Taller de VIH/SIDA Pediátrico, Santiago, Chile, 28-29/05/2010.

19.- González M, Galaz M I, Chávez A, Álvarez A M, Peña A M, Villarroel J, Vizueta E, Wu E, por Comité VIH/SIDA Pediátrico, SOCHIPE. Cohorte Pediátrica
VIH. XXXI Congreso Chileno de Infectología, Puerto Varas, 12-15/XI/2014.

20.- Chávez A. Experiencia chilena con la Norma de Prevención de la TV del VIH. Presentado en III Encuentro Nacional de Mujeres del WFPA, organizado por Women for Positive Action, Santiago, Chile, 10/01/2014.

21.- Chávez A. por Comité de VIH/SIDA Pediátrico, SOCHIPE. Transmisión vertical del VIH en Chile. Presentado en Curso en XVII Curso Nacional de VIH, Santiago, 29 y 30 de agosto de 2014

22.- Ministerio de Salud. Serie de Guías Clínicas Síndrome de Inmunodeficiencia Adquirida,

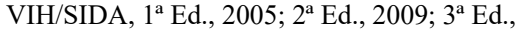
2013. http://www.sidachile.cl/guias/GPCVIH. pdf.

23.- Ministerio de Salud, Chile. Guía Clínica Síndrome de Inmunodeficeincia Adquirida VIH/SIDA, 2009, parte 3. Rev Chilena Infectol 2009; 27: 449-74.

24.- Instituto de Salud Pública (ISP), Ministerio de Salud, Chile. Informativo trimestral resultados diagnóstico virológico infección VIH pediátrica.

25.- Pizzo P H A, Wilfert M C. Antiretroviral treatment for children with HIV Infection. In Pediatrics AIDS: The challenge of HIV in infants, children and adolescents, Pizzo PhA and Wilfert C Eds, 2nd Ed., Wilkins and Wilkins, Baltimore, USA, 1994: 651-87.

26.- CDC. Guidelines for the use on antiretroviral agents in pediatric HIV infection. MMWR. Morbid Mortal Wkly Rep 1998, 47 (RR-4) 1-43. Puestas al día desde el 01/03/ 99 a la fecha (última versión 12/02/2014).

27.- PENTA (Paediatric European Network for Treatment of AIDS of Pediatric HIV-1 infection) Steering Committee. PENTA guidelines, versions 2002, 2009 y, última, 2015. optimizing health in preparation for adult life HIV Med 2015: 28-33. Feb 3. doi: 10.1111/ hiv.12217 http://www.ncbi.nlm.nih.gov/ pubmed/25649230.

28.- WHO. Guidelines on when to start antiretroviral therapy and pre-exposure prophylaxis for HIV. Sept 2015, pags.30-41. http://www.who.int/hiv/ pub/guidelines/earlyrelease-arv/en/

29.- Mofenson L M. Recurrent bacterial, viral and opportunistic infections and their prophylaxis in HIV-infected children. Presentado en XIX Congreso Chileno de Pediatría, La Serena, Chile, Noviembre 1992.

30.- Kovacs A, Schluchter M, Easley K, Demmler G, Shearer W, La Russa P H, et al, for the Pediatric Pulmonary and Cardiovascular Complications of Vertically Transmitted HIV Study Group. Cytomegalovirus infection and HIV-1 disease progresión in infants born to HIV-1-infected women. N Eng J Med 1999; 341: 77-84.
31.- Abrams E J. Opportunistic infections and other clinical manifestations of HIV disease in children. Pediatr Clin North Am 2000; 47: 79-108.

32.- CDC, NHI and IDSA: Treating opportunistic infections among HIV-exposed and infected children. MMWR Morbid Mortal Wkly Rep.2004, 53: RR-14: 1-92.

33.- Villarroel J, Vizueta E, Álvarez A M, Galaz M I, Peña A, Schuffeneger R, et al. Tuberculosis en SIDA y Pediatría. Rev Chilena Infectol 2007; 24: 472-476.

34.- Peña $A$, Larrañaga $C$, Luchsinger $F$, Villarroel J, Chávez A, Wu E, y Comité Nacional de SIDA Pediátrico, Sociedad Chilena de Pediatría. Enfermedad por citomegalovirus en niños chilenos infectados con el virus de la inmunodeficiencia humana. Rev Chilena Infectol 2007; 24: 477-84.

35.- Peña A M, Larrañaga C, Wu E, Álvarez AM, Chávez A, Vizueta E, Galaz M I, Villarroel J, por Comité VIH/SIDA Pediátrico, Chile. Eventos oportunistas y enfermedad por citomegalovirus en niños chilenos infectados con VIH. Presentado en XIII Congreso Latinoamericano de Infectología Pediátrica, SLIPE, IV Congreso Ecuatoriano de infectología, Guayaquil, Ecuador, 12.15/08/09. Libro de resúmenes, VIH-5, pag 37. Actualización en XII Taller de VIH/SIDA Pediátrico, Santiago, Chile, 28-29/05/2010.

36.- Wu E. Compromiso pulmonar por VIH. En Alergia e Inmunología Respiratoria. Quezada A y Zenteno D. Eds., $1^{\text {a }}$ Ed. Editorial Mediterráneo 2013: 229-37.

37.- AIDS Info. Guidelines for the Prevention and Treatment of Opportunistic Infections Among HIV-Exposed and HIV-Infected Children; pags. 2-284, downloaded from http://aidsinfo.nih.gov/ guidelines on 11/6/2013.

38.- Villarroel J, Álvarez Ana M, Chávez A, Cofré J, Galaz M I, Ledesma P, Peña A, Vizueta E, Wu E, por el Comité Nacional de SIDA Pediátrico. Incidencia de cáncer en niños chilenos infectados por VIH XXVI Congreso de Infectología, Viña del Mar, Poster, 23/X/2009, Libro de resúmenes P-68. Rev Chilena Intectol 2015; 32: 672-6.

39.- Wu E. Infección por virus de inmunodeficiencia en niños y adolescentes. Más de 25 años en Chile. Rev Chilena Infectol 2015; 32 (Supl 1): S44-S56.

40.- Villarroel J, Álvarez A M, Chávez A, Wu E, Salvador F. Jóvenes con infección VIH adquirida por transmisión vertical. Expectativas de tener hijos no infectados. XXXI Congreso Chileno de Infectología, Puerto Varas, 12-15/XI/2014, Poster, libro de resúmenes $\mathrm{P}-37$. 